\title{
A EFICIÊNCIA E O EFEITO KALDOR-HICKS: A QUESTÃO DA COMPENSAÇÃO SOCIAL
}

\section{THE EFFICIENCY AND THE KALDOR-HICKS EFFECT: THE ISSUE OF SOCIAL COMPENSATION}

\author{
Martinho Martins Botelho 1
}

\section{RESUMO}

O presente artigo pretende dar uma visão geral a respeito da eficiência econômica segundo os critérios de Nicholas Kaldor e John Hicks, além de tratar com maior particularidade o método desenvolvido por ambos os economistas para a chamada compensação social, que parte da ideia da recuperação das perdas sociais causadas por uma decisão eficientista, no sentido de maximização da riqueza. Trata-se de um dos conceitos de eficiência em Análise Econômica do Direito, ao qual se soma à eficiência alocativa e à eficiência paretiana. Será analisada a eficiência como pressuposto teórico na AED, a eficiência Kaldor-Hicks e a compensação social.

Palavras-chave: Compensação social, Eficiência econômica, Efeito kaldor-hicks

\section{ABSTRACT}

This article aims to give an overview about the economic efficiency according to the criteria of Nicholas Kaldor and John Hicks, besides providing with some particularities the method developed by both economists, the social compensation. It reflects the idea of social recovery of losses caused by an efficient decision in the sense of wealth maximization. This is one of the concepts of efficiency in Economic Analysis of Law, to which is added the allocative efficiency and Pareto efficiency. It will be show the efficiency as a theoretical assumption in EAL, the Kaldor-Hicks efficiency and the social compensation.

Keywords: Social compensation, Economic efficiency, Kaldor- hicks effect

\footnotetext{
1 Doutor em Direito pela USP. Doutor em Teoria Econômica pela UEM. Professor colaborador do Programa de Mestrado em Direito do Centro Universitário Internacional Uninter.
} 


\section{INTRODUÇÃO}

O presente artigo examinará a visão da eficiência Kaldor-Hicks na Análise Econômica do Direito (AED), e a relação da concepção da eficiência com a noção de utilidade, sendo um recurso aplicável no estudo da tomada de decisões mais justas e eficientes.

Tal como será analisado, a teoria da eficiência em AED não representa uma doutrina, mas um elemento teórico relevante no método do Direito e Economia, justamente por existiram concepções distintas.

Fala-se em eficiência alocativa, eficiência de Pareto e eficiência de Kaldor-Hicks (ou critério Kaldor-Hicks), sendo aqui apresentada a última desenvolvida, teoricamente, pelos economistas Nicholas Kaldor (1939) e John Hicks (1939).

Efetivamente, a razão teleológica principal do uso do critério Kaldor-Hicks é captar algumas situações que a eficiência de Pareto não visualiza, mas partindo do ponto de aplicação da noção eficientista das relações socioeconômicas para explicar a tomada de decisões de agentes socio-econômicos.

A teoria da eficiência desenvolvida por Vilfredo Pareto sofreu uma série de críticas, principalmente na questão da consideração de custos de transação zero e da externalidade negativa (DURLAUF, BLUME, 2008).

Na visão de eficiência paretiana, parte-se do pressuposto da realização da melhoria de situação para todas as partes envolvidas em relações socioeconômicas.

Já na eficiência Kaldor-Hicks, uma tomada de decisões pode ter um resultado mais eficiente a partir de uma situação na qual outras pessoas passem por pioras ou deteriorações.

No campo da Epistemologia Jurídica, sabe-se das ideias básicas do ordenamento jurídico fundamentado na noção do direito eficiente. No entanto, na Teoria Econômica que estuda o Direito, a eficiência é um bem incontroverso, mas com uma conclusão controversa.

O presente artigo analisará a questão da eficiência como pressuposto teórico do Law and Economics, a noção de utilidade e a sua mensuração, o comportamento socioeconômico como elemento de estudo da Teoria Econômica, a eficiência Kaldor-Hicksiana e a questão da compensação social e, por fim, traçará uma conclusão.

Pretende-se estabelecer um contraponto entre a eficiência paretiana e a kaldorhicksiana, no sentido de contribuir para o avanço epistemológico da AED. 
Busca-se apresentar, brevemente, a fronteira da noção de eficiência em KaldorHicks na tomada de decisões pelos agentes socioeconômicos.

\section{A eficiência econômica como pressuposto teórico do Law and Economics}

Na linguagem não-jurídica, o signo -eficiênciall acaba sendo associado à mecânica da iniciativa privada, ao dinamismo do mundo dos negócios e, inclusive, à ideia de riqueza.

Porém, na concepção da Análise Econômica do Direito, eficiência representa a otimização ou a maximização de alguma medida de valor (SALAMA, 2008, p. 24).

Em função da escassez de recursos em sistemas econômicos, tal como na teoria robbinsiana do início do século XX, pode-se, exemplificativamente, levar os agentes socioeconômicos à preferência de utilização de fatores de produção voltados à maximização de produtividade (COOTER, ULEN, 1996, p. 79).

Assim, elege-se um componente valorativo, tal como, a proteção do consumidor, do meio ambiente, do trabalhador, entre outro, considerando-o relevante, buscando opções que tenham resultado a maximização desse valor.

Assim, o termo eficiência se relaciona com uma regra de maximização da utilização de riquezas e do bem-estar social, no âmbito da Teoria Econômica. De tal sorte que a noção de eficiência, assim como também compreendido pela AED, passa pelo entendimento do -ótimo de Paretoll ou da eficiência de Pareto (POSNER, 2007, p. 11). ${ }^{1}$

Do ponto de vista normativo, o direito pode gerar resultados de relações socioeconômicas eficientes, além de outros produtos eficientes, sendo a eficiência como um critério geral para aferir se uma norma jurídica é desejável ou não.

No âmbito da Análise Econômica do Direito, o valor procurado na eficiência é relacionado com a ideia de bem-estar social, sendo uma referência da agregação do nível de utilidade inferido por cada agente de determinada sociedade, em razão das consequências de determinada razão política, jurídica ou social (POSNER, 2007, p. 19).

A teoria econômica neoclássica considera que os agentes socioeconômicos racionais possuem preferências para a satisfação das suas necessidades, de níveis de utilidade em situações reais e específicas.

Assim, determinado agente pode resolver beber refrigerante no almoço de domingo ao invés de água e, assim, satisfazer-se mais quando beber refrigerante no almoço com mais 
frequência durante a semana. Com isso, linguisticamente, tal agente associa -beber refrigerantell a um nível de utilidade maior quando associado à decisão -beber águall.

O modelo teórico do bem-estar social representa um meio de agregação geral de todos os indivíduos em determinada social (SALAMA, 2008, p. 24-25).

Com isso, a forma de agregação mais considerada é representada pelo soma dos níveis de utilidade de cada um e de todos os agentes socioeconômicos da sociedade.

A noção de eficiência econômica, tal como já fora explanado, passa pela ideia do economista e sociólogo Vilfredo Pareto, que entendia que uma mudança socioeconômica seria considerada eficiente quando o novo cenário produzisse um produto superior ao status quo ante, sem que ocorressem perdas para nenhum dos atores socioeconômicos envolvidos (COASE, 1960, p. 2).

Com isso, poder-se-ia dizer que haveria uma melhoria de Pareto quando, ao menos, um agente auferisse ganhos sem que outros apresentassem perdas.

Em uma situação na qual os agentes ganhem sem significar a perda para qualquer outro, haveria o Ótimo de Pareto. Em outras palavras, tal situação representaria aquela alcançada quando não existir outra situação tal que seja possível aumentar o bem-estar de um indivíduo sem diminuir o bem-estar de outro indivíduo. Representa um ponto de equilíbrio nas decisões individuais, a partir do qual fica impossível melhorar a situação de um agente socioeconômico sem piorar a situação de outro (FONSECA, s.d.).

No -ótimo de Paretoll, os agentes socioeconômicos não serão induzidos a realizar novas trocas sociais voluntariamente, o que consistiria em um ótimo social, já que a somatória das utilidades individuais seria o maior valor possível (COOTER, ULEN, 1996, p. 41).

O -Ótimo de Paretoll representa um critério de avaliação do bem-estar social, tendo representado na Economia do Bem-estar durante o século XX, o que causou relevantes mudanças nos fundamentos teóricos econômicos (SCHUMPETER, 1948, p. 28).

São vários os casos que podem ser visualizados sob a ótica da eficiência econômica (ou socioeconômica). Pode-se citar: o problema da distribuição de renda pela tributação, a realocação de recursos por meio de contratos, o papel do Estado na propriedade privada etc.

Assim, o sistema jurídico arquitetará movimentações na alocação de recursos na sociedade, através de elementos econômicos, morais, políticos, entre outros. E, nesse contexto, haverá de se questionar? Seriam mecanismos eficientes em Pareto?

São poucas as situações nas quais o ordenamento jurídico e/ou o Poder Judiciário tome decisões que resultem em ganhos para todas as partes envolvidas, ou seja, que gere um 
ótimo paretiano.

Com isso, uma decisão judicial é tratada como um sistema topológico fechado, onde um ganhador pressupõe o aumento de bem-estar de uma parte e a redação da pretensão/bem-estar de outra parte. Em outras palavras, uma sentença judicial acaba estando fora do conceito de Pareto-eficiência.

É por isso que, além da eficiência econômica do tipo paretiana, existe o conceito de eficiência de Kaldor-Hicks, por meio do qual se visualizam ganhos sociais maiores do que perdas individuais globais, por meio de um sistema de compensação social.

Os dois modelos teóricos de eficiência também passam pela discussão sobre a noção de utilidade. É o que será visto a seguir. 


\section{O comportamento do agente social como objeto de estudo da Teoria Econômica}

O comportamento dos agentes sociais é baseado nas ações positivas ou negativas movidas pela vontade de um ganho, ou seja, de um interesse.

Em outras palavras, um determinado indivíduo $\alpha$ realiza determinada ação, a qual proporciona ao mesmo um ganho $\mathrm{G}_{\alpha}$ Por conseguinte, tal ganho provoca uma externalidade negativa (um prejuízo) a um indivíduo $\beta$, notacionando-se um $\mathrm{P}_{\beta}$.

Para fins da hipótese dos dois indivíduos mencionados, o ganho social total (GS) consubstancia-se pela diferença entre o ganho individual de um agente $\left(G_{\alpha}\right)$ e a perda individual de outro agente $\left(\mathrm{P}_{\beta}\right)$, vale dizer (BOTELHO, WINTER, 2014):

$\mathrm{GS} \equiv \mathrm{G}_{\alpha}-\mathrm{P}_{\beta}$, sendo que $\mathrm{G}$ e $\mathrm{P} \in \in \mathbb{R} \neq 0, \mathrm{e}>0$

A partir desse conceito de ganho social (equação identidade 1), pode-se avaliar que as ações socialmente aceitáveis ${ }^{2}$ são voltadas para o uso de recursos econômicos para que o outro indivíduo $\alpha$ (ou seja, o beneficiado) não implemente a ação desejada.

Com isso, a partir de tal arquitetura relacional, sugere-se que ocorram custos sociais sem uma contrapartida direta (LOEVINGER, 1964, p. 73).

Em outras palavras, o agente socioeconômico $\alpha$ está vinculado a um espaço dimensional A, o qual está relacionado funcionalmente por recursos econômicos lá gerados, $\mathrm{Y}$

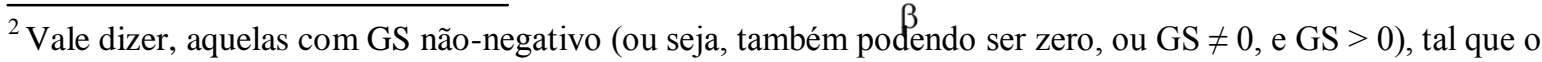
comportamento maximizante ou ótimo do agente sócio-jurídico (o qual fora prejudicado).
} 
$=\mathrm{f}\left(\mathrm{A}, \mathrm{E}_{\alpha}\right)$, onde $\mathrm{E}$ é o esforço de $\alpha$ que gera determinada situação de utilidade ou de bemestar, considerado como U (Y, E $\alpha)$.

Intuitivamente, a mencionada função utilidade $U$ é diretamente proporcional à função de utilização de recursos econômicos do indivíduøe inversamente proporcional ao seu esforço $E_{\alpha}$.

$\mathrm{O}$ agente socioeconômico maximizador escolherá um nível de esforço, $\mathrm{E}_{\alpha}{ }^{*}$, com a finalidade de maximizar o seu bem-estar, $\mathrm{BE}(\mathrm{A})$, o qual é diretamente proporcional com ao seu espaço econômico (BOTELHO, WINTER, 2014):

$\mathrm{BE}(\mathrm{A})=\operatorname{máx} \mathrm{E}_{\alpha} \mathrm{U}\left[\mathrm{f}\left(\mathrm{A}, \mathrm{E}_{\alpha}, \mathrm{E}_{\alpha}\right)\right.$

Interpretando-se a equação definicional (2), infere-se que, quando o agente tiver como vizinho um agente $\beta$ vinculado a uma dimensão econômica $B$, caso o agente $\alpha$ aumente a sua escolha em x unidades à custa da dimensão do vizinho $\beta$, então haverá de se melhorar o seu bem-estar porque a sua utilidade passaria a ser $\mathrm{BE}(\mathrm{A}+\mathrm{x})$ maior do que $\mathrm{BE}(\mathrm{A})$ (BOTELHO, WINTER, 2014).

Formalizando-se:

$\operatorname{BEA}(\mathrm{A}+\mathrm{x})>\mathrm{BE}(\mathrm{A})$, se $\mathrm{x}>0, \mathrm{x} \in \mathbb{R}$

No entanto, em tal hipótese, haverá uma piora da situação do agente $\beta$, já que a aquisição adicional da unidade $\mathrm{x}$ por $\alpha$ provoca uma menor disponibilidade na dimensão econômica total.

Assim, $\mathrm{BE}(\mathrm{B}-\mathrm{x})<\mathrm{BE}(\mathrm{B})$, se $\mathrm{x}>0$ e $\mathrm{x} \in \in \mathbb{R}, \mathrm{x}>0$

A partir da definição (1), em termos sociais gerais,

$\mathrm{GS}(\mathrm{x})=\mathrm{BE}(\mathrm{A})+\mathrm{BE}(\mathrm{B})$

$\mathrm{GS}(\mathrm{x})=[\mathrm{BE}(\mathrm{A}+\mathrm{x})-\mathrm{BE}(\mathrm{A})]+[\mathrm{BE}(\mathrm{B})-\mathrm{BE}(\mathrm{B}-\mathrm{x})]$

A equação (5) representa que o ganho individual do agente $\alpha$ é -retiradoll da parte x da dimensão econômica do agente $\beta$. 
Tal hipótese levou em consideração apenas a parte $\mathrm{x}$, a qual poderia ser inferida como um ganho social do indivíduooque se apropria da parte $\mathrm{x}$ da dimensão econômica do agente $\beta$ (BOTELHO, WINTER, 2014).

Destarte, em matéria de raciocínio de cálculo em limites, quando a dimensão x é infinitesimal $(x \rightarrow \infty)$, o ganho de bem-estar do agente $\alpha$ e a perda do agente $\beta$ é determinado pela derivada primeira da função de bem-estar, $\mathrm{BE}$, vale dizer, $\mathrm{BE}(\mathrm{A})$ ' e $\mathrm{BE}(\mathrm{B})$ ', respectivamente.

Assim, um ganho social infinitesimal poderá ser dado por:

$$
\begin{aligned}
& \mathrm{GS}^{\prime}=\Delta\left(\mathrm{V}^{\prime}\right) \\
& \mathrm{GS}^{\prime}=\mathrm{V}(\mathrm{A})^{\prime}-\mathrm{V}(\mathrm{B})^{\prime}
\end{aligned}
$$

Infere-se que o ponto ótimo social (de máxima eficiência) seria dado quando a derivada primeira do ganho social seja igual a zero, vale dizer, na equação (6), GS' $=0$, tal como formalizando a seguir:

$0=\mathrm{V}(\mathrm{A})^{\prime}-\mathrm{V}(\mathrm{B})^{\prime}$

$\mathrm{V}(\mathrm{A})^{\prime}=\mathrm{V}(\mathrm{B})^{\prime}$

V(A)' representa os recursos socioeconômicos que o agente $\alpha$ utilizará, na tentativa de utilizar também recursos da dimensão econômica do agente $\beta$.

Com isso, nesse modelo teórico de sistema social sem regras jurídicas, os indivíduos disputam entre si para conseguir utilizar recursos socioeconômicos existentes na dimensão econômica dos outros agentes, os quais se defendem (LOEVINGER, 1952, p. 475). Existe uma -lutall por recursos socioeconômicos entre os indivíduos, incluindo também direitos de propriedade.

As ações dos diversos indivíduos se anulariam, causando, uma diminuição do bem-estar individual, respectivamente, nas seguintes relações:

$\mathrm{V}(\mathrm{A} \mid$ com a existência de vizinho $\beta)=\mathrm{V}(\mathrm{A})-2 \mathrm{~V}(\mathrm{~A}){ }^{\prime}$

$\mathrm{V}(\mathrm{B} \mid$ com a existência de vizinho $\alpha)=\mathrm{V}(\mathrm{B})-2 \mathrm{~V}(\mathrm{~B})$ ' 
A perda social pela inexistência de um ordenamento jurídico que resolva o -conflito de interesses\| ou a -colisão de interesses $\|$ entre os agentes $\alpha$ e $\beta$ será igual a 2 $\left[\mathrm{V}(\mathrm{A})^{\prime}+\mathrm{V}(\mathrm{B})^{\prime}\right]$.

Ademais, teoricamente, ainda se poderão inferir outros motivos pelos quais existirão perdas sociais em razão da inexistência de -regras jurídicas do jogo socialll (um sistema legal, em outras palavras), tal como acontece na dificuldade da utilização do ganho resultante na divisão do trabalho, o que pode ser formalizado matematicamente pela relação (BOTELHO, WINTER, 2014):

$\mathrm{f}\left(\mathrm{A}+\mathrm{B}, \mathrm{N}_{\alpha} *+\mathrm{N}_{\beta} *\right)>\mathrm{f}\left(\mathrm{A}, \mathrm{N}_{\alpha} *\right)+\mathrm{f}\left(\mathrm{B}, \mathrm{N}_{\beta} *\right)$

\section{A noção de utilidade e a sua mensuração}

Vários instrumentos foram formulados pela teoria econômica normativa, a qual inicia as suas fundamentações com a ideia de utilidade, ou seja, a concepção ou a medida de um bem econômico.

A teoria econômica apresenta vários dilemas e discordâncias teóricas, existindo divergências sobre a teoria da utilidade para o bem-estar social e da função do bem-estar na política pública econômica. No entanto, a teoria econômica acaba sendo pacífica ao concordar sobre a proposição da maior utilidade sendo uma boa premissa, ceteris paribus (BLACK, 1948, p. 24).

$\mathrm{Na}$ evolução histórica da teoria econômica, uma das maneiras de se interpretar a utilidade é aquela associada com as ideias do filósofo inglês e jurista Jeremy Bentham.

Na visão benthamniana, a utilidade poderia ser concebida em termos de prazer ou de ausência do sofrimento. Nesse sentido, Bentham sustentava que as leis e a política poderiam ser mensurados por meio de um -cálculo hedonistall. Com isso, uma melhor lei ou uma melhor política poderia produzir mais unidades de prazer, denominadas como hedons (BLACK, 1948, p. 25).

Porém, a percepção de Betham não era suficiente para criar uma base fundamental para a mensuração da utilidade para a ciência econômica, em razão da inexistência de um método rigoroso para a medição -realll de valores hedônicos.

Teoricamente, os economistas acabaram interpretando a ideia de utilidade, levando 
em consideração as preferências, ou seja, valores subjetivos que os agentes socioeconômicos atribuem para coisas ou estados. Assim, se um agente socioeconômico prefere estado de coisas do tipo $\mathrm{X}$ ao estado de coisas do tipo $\mathrm{Y}$, então $\mathrm{X}$ teria mais utilidade do que $\mathrm{Y}$ para aquele agente (FIANI, 2002, p. 33).

As mudanças nas preferências, como base para uma teoria dinâmica da utilidade, oferece aos economistas a possibilidade de compreender determinados problemas de avaliação comportamental, e inclusive na Economia Institucional e na Análise Econômica do Direito.

E qual seria o mecanismo para a medição de tais preferências?

É nesse sentido que a Teoria Econômica passa a distinguir as visões ordinais e cardinais da utilidade (FIANI, 2002, p. 33).

Uma função de utilidade ordinal para determinado indivíduo consiste na ordenação de possíveis estados ou de coisas, de tal sorte que esse indivíduo prefere uma opção $\mathrm{X}$ ao invés de $\mathrm{Y}$, mas não que $\mathrm{X}$ fosse muito melhor do que $\mathrm{Y}$, ou um pouco melhor (FIANI, 2002, p. 34).

Uma função de utilidade cardinal acaba representando apenas uma opção total para as possibilidades existentes. Essa distinção entre as utilidades cardeal e ordinal é relevante para o utilitarismo na teoria da escolha (FIANI, 2002, p. 36).

O utilitarismo poderia ser considerado na referência à visão de uma ação caso ela maximize a utilidade quando comparada com todas as ações alternativa possíveis.

As dificuldades enfrentadas pelo utilitarismo estão relacionadas com a história da Teoria Econômica do Bem-estar, campo de estudos tipicamente normativo da ciência econômica (WALRAS, 1874, p. 47).

$\mathrm{Na}$ Teoria Econômica do Bem-estar, a cardinalidade e a comparabilidade interpessoal apresentam problemas com a medição da utilidade. O maior desafio para a Teoria do Bem-estar foi desenvolver um método que produza avaliações científicas refinadas e rigorosas, mas sem a exigência da noção de utilidades cardinal comparável entre indivíduos, tal como acontece na Teoria Neoclássica do século XIX (NORTH, 1994, p. 359).

É neste ponto que a análise paretiana acaba entrando em cena na Teoria Econômica e na Análise Econômica do Direito (ZYLBERSZTAJN, SZTAJN, 2005, p. 59).

Assim, pode-se supor que todas as informações sobre as utilidades individuais seja ordinal e não-comparável interpessoalmente.

Em outras palavras, cada indivíduo pode classificar os estados de ordem das coisas, 
mas outros não conseguem comparar a ordem dos diversos estados individuais (CABALLERO GARCÍA, 2006, p. 18).

O princípio do Pareto-fraco estabelece que um estado de coisas P é socialmente preferível a estado de coisas $\mathrm{Q}$, se o ranking original $\mathrm{P}$ for socialmente preferível ao estado de coisas Q.

Assim, o princípio do Pareto-fraco não leva a considerações maiores, porque a uniformidade de preferências entre todas as pessoas é bastante raro, o que seria necessário analisar melhor a situação na qual exista o princípio do Pareto-forte, ou da eficiência no sentido de Pareto.

\section{A eficiência Kaldor-Hicks}

Imagine-se uma situação na qual as suas externalidades afetem terceiras partes. Suponha-se que os mercados não possam alcançar um resultado Pareto-eficiente, nesse caso.

Tal hipótese parece ser precisa em razão dos custos de transação elevados, como no caso dos impactos da poluição sobre indivíduos, e a negociação é impraticável ou onerosa.

Alguns resultados que sejam Pareto-eficientes em ambientes com custo de transação zero, são Kaldor-Hicks-eficientes (STRINGHAM, 2001, p. 42.

Assim, a AED normativa é ampliada, em Kaldor-Hicks para uma ampla gama de situações nas quais as externalidades e os custos de transação impeçam os mercados em atingir resultados Pareto-eficientes, estando destacada a relevância dos ganhadores compensarem os -perdedores de direitos $\|$ a uma alocação de bens, no sentido de -compensar\| as perdas.

Com isso, a utilidade prática do conceito de eficiência de Pareto é viabilizada pela complementação teórica de Kaldor-Hicks (STRINGHAM, 2001, p. 43).

As críticas da eficiência, sejam paretiana ou kaldor-hicksiana, centralizam as questões na questão da atratividade pelas quais as políticas legais possam ser julgadas. Tratase, efetivamente, de uma questão complexa.

Quando a ideia paretiana é aplicada a transações de mercado, as preferências (ou utilidades) são interpretadas como uma função da vontade de se envolver em transações. Porém, a disposição em pagar é uma função da riqueza disponível.

O princípio de eficiência no sentido de Pareto consiste na ideia que o estado de coisas $\mathrm{M}$ é socialmente preferível ao estado de coisas $\mathrm{N}$, se pelo menos uma pessoa ocupa o 
M maior do que $\mathrm{N}$ e ninguém ocupa o $\mathrm{N}$ maior que o M (PARETO, 1971, p. 87).

Em outras palavras, uma dominância forte de Pareto diz que é bom uma pessoa fazer do que ninguém fazer, o que seria pior.

A Nova Economia do bem-estar foi construída na visão de que as operações socioeconômicas em mercados, sem externalidades, satisfaz a condição forte de Pareto.

A única diferença entre os estados $\mathrm{M}$ e $\mathrm{N}$ é que, em $\mathrm{M}$, os agentes socioeconômicos em A e B se envolvem em uma troca (dinheiro por livros, frangos por sapatos) onde ambos preferem o resultado de trocas. Assim, a troca é Pareto-eficiente e, portanto, satisfaria o princípio de Pareto-forte (AMOROSO, 1938, p. 10).

Um estado de coisas em que não seja possível nova medidas eficientes de Pareto é chamada de Pareto-ótima. A suposição sobre externalidades é, naturalmente, fundamental. No caso de existência de externalidades, não seria possível trocas socioeconômicas do tipo Pareto-eficiente.

A diferença fundamental entre Kaldor-Hicks e Pareto reside na possibilidade de se aceitar uma mudança social eficiente mesmo quando o incremento do bem-estar se uma parte causa a redução do bem-estar em outra, mas com a manutenção do grau de satisfação do -perdedor de bem-estar\| por uma recompensa ou compensação (STRINGHAM, 2001, p. 47; RAWLS, 1971, p. 17).

Em razão da eficiência de Pareto não assumir situações de externalidades negativas, tal modelo acaba tendo limitações significativas em termos conceituais. Exemplificativamente, existem várias questões sobre políticas jurídicas nas quais a presença conceitual de externalidades é importante, tal como no caso clássico da poluição.

Assim, se uma firma industrial poluir o ar ou a água, a sua ação poderá causar danos a terceiros, tal como em situações de externalidades. Caso uma pessoa sofra uma perda, quando passe de uma situação $\mathrm{P}$ para $\mathrm{Q}$, então essa dinâmica não é considerada Paretoeficiente (PARETO, 1971, p. 52).

Se a eficiência de Pareto fosse o único princípio normativo disponível na Teoria da Análise Econômica do Direito, a consequência seria que os economistas e juristas não teriam como considerar importantes questões, tal como aquelas analisadas na Análise Econômica do Direito Ambiental.

É nesse sentido que se considera a eficiência em Kaldor-Hicks, como sendo uma implicação normativa da AED.

A eficiência Kaldor-Hicks é amplamente aceita na teoria econômica, sendo também 
considerada pela Análise Econômica do Direito, principalmente quando se parte do pressuposto da teoria econômico-jurídica contemporânea de que os julgadores (juízes), implicitamente, a utiliza em decisões e/ou julgados específicos.

Aliás, até mesmo Richard Posner, que baseou a sua eficiência econômica em fundações paretianas, defendia o uso de padrões Kaldor-Hicks em decisão de casos judiciais (POSNER, 2007, p. 42).

Bryan Caplan (1999, p. 824) chega até mesmo a defender o uso da eficiência kaldor-hicksiana, contra-argumentando economistas do mainstream austríaco céticos da teoria neoclássica do bem-estar sócio-econômico-jurídico.

Caplan (1999, p. 835) complementa:

O critério de eficiência tem muitas vantagens sobre a abordagem de Rothbard. Particularmente, tal critério permite alcance a eficiência em julgamentos relacionados como o mundo real, tal como para julgar que o comunismo era ineficiente, ou que o controle da renda é ineficiente ou que a atos de contrafação (pirataria) era ineficiente. ${ }^{3}$

Os seguidores da visão de Kaldor-Hicks acreditam que elementos quantitativos, incluindo instrumentos lógico-matemáticos, seriam úteis para se avaliar a eficiência de diferentes situações.

Muito embora se possa considerar como apropriado a capacidade de se julgar determinadas políticas jurídicas utilizando-se o mencionado padrão de eficiência, alguns economistas ainda argumentam que tais ideias não poderiam ser utilizadas por falta de consistência lógica.

Tal como discorreu Gerald O’Driscoll (1980, p. 359) os defensores das ideias de políticas jurídicas eficientes em Kaldor-Hicks partem do ponto que o problema do cálculo é necessário para as suas considerações, tendo em vistas envolver o padrão de maximização do bem-estar nas fundamentações econômicas positivas e normativas.

A necessidade de se encontrar uma melhor situação do que outra em um ambiente de decisão, fez com que a teoria econômica do bem-estar se dedicasse ao estudo do nível de comportamento dos agentes socioeconômicos.

Assim, os teóricos econômicos passaram a formular uma série de indagações sobre o nível individual de seleções, incluindo-se questionamentos como: será que A é melhor que 
B? E caso B seja melhor, o quão seria melhor? Quanto um determinado agente socioeconômico estaria interessado em obter A ao invés de B?

Tais questões, além de serem levadas ao nível individual, também podem ser evocadas no espaço da sociedade civil organizada.

Já no século XIX, os economistas utilitaristas indicavam que o nível de felicidade das pessoas (o que se poderia traduzir, posteriormente, como satisfação ou utilidade) poderia ser medido de acordo com determinados físicos (STRINGHAM, 2001, p. 48).

Em síntese, os utilitaristas do século XIX entendiam a utilidade como um método comparativo interpessoal, baseado em lógicas métricas. Com isso, seria possível avaliar, ao nível individual e social, determinadas questões acerca de quando uma decisão X seria melhor do que uma decisão Y, e por quanto seria melhor.

\section{A compensação social em Kaldor-Hicks}

Tal como visualizado, a eficiência no sentido Kaldor-Hicks, considera um resultado mais eficaz se um ótimo de Pareto puder ser alcançado por determinado agente com uma compensação suficiente dos que ficaram uma um estado de coisas melhor do que aqueles que ficaram pior do que antes.

Em outras palavras, na ideia kaldor-hicksiana, é justificável a situação de agentes em uma situação pior do que se encontravam anteriormente, desde que outros agentes em situações melhores do que antes compensem a perda dos demais (STRINGHAM, 2001, p. 49).

Na visão paretiana, pela eficiência, um resultado decisional seria mais interessante se ao menos uma pessoa melhora e nada piore. Parece ser uma ideia simples de se encontrar a melhoria da eficiência socioeconômica decisional (SCITOVSKY, 1941, p. 75).

Porém, fala-se que, na prática socioeconômica, é quase impossível uma determinada decisão, uma ação social, ser tomada sem que piore a situação de bem-estar de outro agente.

Em condições ideais, decisões involuntárias (alguém que decidisse pelo agente, mas não ele próprio), seria possível uma melhoria paretiana, com benefícios mútuos e impactos desses benefícios para todos. 
No entanto, no mundo real, o mais comum são decisões voluntárias dos indivíduos, e tais decisões seriam difíceis de serem superior-Pareto, em razão de existirem custos sociais, principalmente para os terceiros que não tomam tais decisões (SCITOVSKY, 1941, p. 80).

È nesse sentido que por meio do critério de eficiência Kaldor-Hicks, um resultado seria mais eficiente se os que se beneficiam da mudança possam, teoricamente, compensar os que sofrem as consequências, constituindo em um resultado melhor de acordo com Pareto.

Assim, trocas voluntárias que causam contaminação seria uma melhoria de KaldorHicks se os compradores e os vendedores estivessem dispostos a realizar a transação, com a compensação plena das vítimas da contaminação (HICKS, 1939, p. 700).

A diferença-chave da questão apontada é a indenização. O critério de Kaldor-Hicks não supõe que se realize uma compensação, mas que exista uma possibilidade de compensação.

Destarte, na eficiência kaldor-hicksiana, um resultado mais eficiente poderia, efetivamente, deixar alguns agentes socioeconômicos em pior situação. Por outro lado, a eficiência paretiana exige que cada parte tenha resultados melhores, ou ao menos não-piores.

Enquanto que cada melhoria paretiana seria uma melhoria kaldor-hicksiana, a maioria da melhorias em kaldor-hicks não estariam de acordo com o modelo de melhorias eficientes no sentido de Pareto (HICKS, 1939, p. 701).

Assim, o conjunto de melhorias paretianas é um subconjunto próprio de melhorias Kaldor-Hicks, relacionando-se com uma maior flexibilidade e aplicabilidade dos critérios de Kaldor-Hicks, em relação com os critérios de Vilfredo Pareto.

Em geral, o método de eficiência de Kaldor-Hicls é utilizado como mecanismos de provas na determinação da possibilidade de existência de uma melhora paretiana. É nesse sentido que passam a serem utilizadas, exemplificativamente, para determinar se uma atividade conduz um sistema econômico para a eficiência paretiana.

Assim, uma mudança nas decisões de determinados agentes socioeconômicos pode gerar melhorias e também piorias para outros, o que parece ser relevante determinar se os ganhos sociais compensariam as perdas sociais, e vice-versa.

A compensação social de Kaldor-Hicks se aplica à teoria econômica do bem-estar e na análise econômica da empresa, principalmente a partir da análise de custo-benefício.

$\mathrm{Na}$ análise de custo-benefício, uma determinada decisão (um projeto, por exemplo) de uma estrada seria avaliada mediante a comparação entre os custos totais (gastos com a construção, custos ambientais etc.) com o total de benefícios (para as empresas de viação, 
melhorias para o comércio local ou regional etc.)

Uma questão problemática no critério de Kaldor-Hicks é a da determinação da compensação total. Isso porque as preferências individuais dos agentes socioeconômicos somente podem ser reveladas por meio de uma transação voluntária (HICKS, 1939, p. 704).

Isso originaria o problema fundamental da determinação teórica do montante prático dessa compensação. Objetivamente, perguntar-se-ia como saber quanto estará disposto um indivíduo a sacrificar a sua decisão em função da decisão de outro?

Resta dizer ainda que a função de bem-estar social total é determinada pela agregação dos bem-estares sociais individuais, na teoria kaldor-hicksiana:

$$
\mathrm{BE}_{\text {total }}=\mathrm{BE}_{1}+\mathrm{BE}_{2}+\mathrm{BE}_{3}+\ldots+\mathrm{BE}_{\mathrm{n}} \text {, onde } n \in \mathbb{N} \text {, e } n \neq 0
$$

Com isso, pode-se dizer que o aumento do bem-estar dos ganhadores (BE) deve compensar a redação do bem-estar dos perdedores, tal como analisado na equação 1.

Quanto às críticas feitas à eficiência kaldor-hicksiana, em suma, a principal consiste na despreocupação com o problema da distribuição social das perdas compensadas, o que, por vezes, acaba sendo feita desproporcionalmente (SCITOVSKY, 1941, p. 78).

Ademais, a comparação entre os ganhos e as perdas, na prática, é impossível em razão das diferenças de valores marginais para cada grupo de agentes socioeconômicos. Com isso, a compensação social nem sempre acaba sendo justa, e ainda assim passa a gerar perdas sociais, sendo impossível a compensação dita (SCITOVSKY, 1941, p. 79).

Além disso, a mensuração dos ganhos e das perdas sociais se dá em momentos temporais distintos, o que também relativa e torna impossível a compensação social completa e justa, ainda mais quando se fala em preferências pessoais no tempo (SCITOVSKY, 1941, p. 81).

\section{Conclusão}

A eficiência representa uma das ideias basilares da normatividade jurídica e da Teoria Econômica, a qual passou a ser trabalhada em Pareto e, posteriormente, em KaldorHicks.

A finalidade do presente artigo foi tratar sobre a questão da eficiência socioeconômica de Kaldor-Hicks como método para a compreensão da teoria da eficiência em 
Análise Econômica do Direito.

O que se almejou construir foi a visão de que, em Kaldor-Hicks, é possível a construção da noção de perdas individuais em detrimento de ganhos sociais maiores, o que é considerado o critério de compensação social, estando inclusive tal critério longe de conotações éticas, em razão da influência da teoria econômica liberal do individualismo.

No âmbito da Teoria do Direito, inferir que o jurista ou o aplicador do direito demande as suas decisões do próprio ordenamento jurídico parece ser um reducionismo exagerado, tendo em vista que os valores jurídicos puros, fora de um pensamento valorativo econômico, é impossível.

Haverá de o Direito ser visto como um meio, um instrumento que possibilite a busca de algo em sua razão existencial. Com isso, a sua interpretação passará a ser cheia de um conteúdo e a AED trata de imaginá-lo como o sistema de procura da eficiência socioeconômica na satisfação dos desejos ilimitados inerentes aos seres humanos.

Em suma, a noção da eficiência na abordagem de Kaldor-Hicks em AED tem uma tripla função na visão da interpretação do fenômeno jurídico:

a) Compreensão do valor de eficiência do sistema jurídico e inclusive das sentenças judiciais;

b) Previsão dos impactos normativos ex-post nas relações socioeconômicas, principalmente no condizente aos ganhos e perdas de agentes socioeconômicos envolvidos em relações jurídicas;

c) Visualização do direito como um feixe de possibilidades para o implementador de políticas alcançar determinada finalidade socioeconômica, principalmente na possibilidade de se pensar sobre a compensação social por perdas causadas pelo Direito.

O critério desenvolvido por Nicholas Kaldor e John Hicks trata, com particularidades, da teoria da utilidade racional, sendo sopesado a ideia da recuperação das perdas sociais em função de decisões maximizadoras da riqueza.

Representa uma das bases teóricas da eficiência paralelamente às outras visões sobre o eficientismo em Análise Econômica do Direito, além da concepção paretiana de eficiência. 


\section{REFERÊNCIAS}

AMOROSO, Luigi. Vilfredo Pareto. Econometrica, vol. 6, p. 1-21, 1938.

DURLAUF, Steven N.; BLUME, Lawrence E. The new Palgrave dictionary of economics. $2^{\text {nd }}$ ed. London: Palgrave McMillan, 2008.

BLACK, Duncan. On the rationale of group decision making. Journal of Political Economy. p. 23-34, 1948.

BOTELHO, Martinho Martins; WINTER, Luís Alexandre Carta. A contribuição da modelagem matemática para a Análise Econômica do Direito. VI Congresso Anual da Associação Mineira de Direito e Economia, agosto de 2014. Disponível em: http://www.congresso.amde.org.br/index.php/CONGRESSO/VI_AMDE/paper/view/75/4 5- Acesso em: 05 de abril de 2016.

CABALlERO GARCíA, José. La Teoría de la justicia de John Rawls. Revista de Ciencias Sociales de la Universidad Iberoamericana, vol. 1, n. 2, p. 1-22, 2006.

CAPLAN, Bryan. The Austrian search for realistic foundations. Southern Economic Journal, vol. 65, n. 4, p. 823-838.

COASE, Ronald Harry. The problem of social cost. Journal of Law and Economics, Chicago, vol. 3, n. 1, p. 1-44. 1960.

COOTER, Robert; ULEN, Thomas. Law and Economics. $2^{\text {nd }}$ ed. California: AddisonWesley, 1996.

FIANI, Ronaldo. Teoria dos custos de transação. In KUPFER, D.; HASENCLEVER, L. Economia Industrial. 2a. ed. Rio de Janeiro: Campus, 2002.

FONSECA, Gonçalo L. The Paretian system: scitovsky reversals and the double criteria. [s.l.]: $\quad\left[\begin{array}{lllll}\mathrm{s} . & \mathrm{ed} .] & \text { [s. } & \text { d.] } & \text { Disponível em: }\end{array}\right.$ http://www.newschool.edu/nssr/het/essays/paretian/paretosocial.htm - Acesso em: $10 \mathrm{de}$ fevereiro de 2016.

HICKS, John. The foundations of Welfare Economics. The Economic Journal, vol. 49, n. 196, p. 696-712. 1939.

KALDOR, Nicholas. Welfare propositions in Economics and interpersonal comparisons of utility. The Economic journal, vol. 49, n. 195, p. 549-552, 1939.

LOEVINGER, Lee. Jurimetrics: the methodology of legal inquiry, Jurimetrics: the methodology of legal inquiry. Law and contemporary problems, n. 28, p. 05-35, 1963.

NORTH, Douglas. Economic performance through time. The American Economic Review, 
n. 84 , n. 3, p. 359-168, junho de 1994.

O'DRISCOLL JUNIOR, Gerald P. ; Justice, efficiency and the economic analysis of law: comment on fried. Journal of Legal Studies, vol. 8, p. 355-366, 1980.

PARETO, Vilfredo. Manual of Political Economy. London: Augustus M. Kelley 1971.

POSNER, Richard Allen. Economic analysis of law. $7^{\text {th }}$ ed. Austin, TX: Wolters Kluwer, 2007.

RAWLS, John. A theory of Justice. Cambridge: Harvard University Press, 1971.

SALAMA, Bruno Meyerhof. O que é pesquisa em Direito e Economia? Cadernos Direito GV, São Paulo, vol. 5, n. 2, março de 2008, p. 24-25.

SCITOVSKY, Tibor. A note on welfare propositions in Economics. The Review of Economic studies, vol. 9, n. 1, p. 77-88, 1941.

SCHUMPETER, Joseph. Vilfredo Pareto, 1848-1923. Quarterly Journal of Economics, 1948.

STRINGHAM, Edward. Kaldor-Hicks efficiency and the problem of central planning. The Quarterly Journal of Austrian Economics, vol. 4, n. 2, p. 41-50, 2001.

WALRAS, Léon. Elements of pure economics: or the theory of social wealth. 1874.

ZYLBERSZTAJN, Décio; SZTAJN, Rachel. Direito e Economia: análise econômica do Direito e das organizações. Rio de Janeiro: Elsevier, 2005. 